\title{
Erratum to: Towards Robot-Assisted Echocardiographic Monitoring in Catheterization Laboratories
}

\section{Usability-Centered Manipulator for Transesophageal Echocardiography}

\author{
Christina Pahl $^{1,2} \cdot$ Henning Ebelt ${ }^{3} \cdot$ Mostafa Sayahkarajy $^{2} \cdot$ Eko Supriyanto $^{4} \cdot$ \\ Amiliana Soesanto 5
}

Published online: 15 September 2017

(C) Springer Science+Business Media, LLC 2017

\section{Erratum to: J Med Syst}

https://doi.org/10.1007/s10916-017-0786-4

The original version of this article unfortunately contained a mistake. The family name of Mostafa Sayahkarajy was incorrectly spelled as Sayahkaraji. The original article has been corrected.

The online version of the original article can be found at https://doi.org/ 10.1007/s10916-017-0786-4

Christina Pahl

christina.pahl@tu-ilmenau.de

1 Biomechatronics Group, Faculty of Mechanical Engineering, Technische Universitaet Ilmenau, 98693 Ilmenau, Germany

2 Faculty of Biosciences and Medical Engineering, Universiti Teknologi Malaysia, 81310 Johor Bahru, Malaysia

3 Klinik für Innere Medizin II/ Kardiologie und Internistische Intensivmedizin Katholisches Krankenhaus, „St. Johann Nepomuk“, Haarbergstrasse 72, 99097 Erfurt, Germany

4 Advanced Diagnostics and Progressive Human Care Research Group, IJN-UTM Cardiovascular Engineering Centre, Faculty of Biosciences and Medical Engineering, Universiti Teknologi Malaysia, 81310 Johor Bahru, Malaysia

5 Department Cardiology \& Vascular Medicine, Faculty of Medicine Universitas Indonesia/ National Cardiovascular Center "Harapan Kita", Jakarta 11420, Indonesia 